\author{
Klaudia KUJAWSKA ${ }^{1}$ \\ Janusz RAK ${ }^{2}$
}

\title{
ANALIZA I OCENA STRAT WODY WODOCIĄGU MIASTA MIELCA
}

\begin{abstract}
W celu obniżenia kosztów związanych z uzdatnianiem i dostarczaniem wody, należy przeprowadzać działania modernizacyjne, opierając je na analizie dotyczącej strat wody. W pracy przedstawiono analizę i ocenę strat wody, przeprowadzoną na podstawie danych udostępnionych przez Zakład Wodociągów i Kanalizacji w Mielcu. Otrzymane dane dotyczą struktury sieci wodociągowej miasta Mielca oraz bilansu ilościowego wody w latach 2012-2014. Na tej podstawie wyznaczono podstawowe wskaźniki strat wody według International Water Association. Wyznaczono następujące wskaźniki start wody: procentowy (WS), jednostkowy start rzeczywistych (RLB), objętości wody niedochodowej (MRWB), start nieuniknionych (UARL), infrastrukturalny indeks wycieków (ILI). Na podstawie kategorii podanych prze IWA, możemy zauważyć, że w roku 2014 mielecka sieć wodociągowa zaliczała się do sieci o bardzo dobrym stanie technicznym. Otrzymane wartości wskaźników strat wody w mieleckim systemie wodociągowym są porównywalne do wartości wskaźników uzyskanych w innych systemach zbiorowego zaopatrzenia w wodę w Polsce.
\end{abstract}

Słowa kluczowe: straty wody, wskaźniki strat wody, zużycie wody, system zaopatrzenia w wodę

\section{Wprowadzenie}

Mielec to miasto o powierzchni $46,89 \mathrm{~km}^{2}$, położone $\mathrm{w}$ południowowschodniej Polsce, w województwie podkarpackim. Liczba mieszkańców wynosi około 61000 . Miasto słynie przede wszystkim z branży lotniczej i motoryzacyjnej. Na przełomie lat 1937 - 1939 powstały tutaj Polskie Zakłady Lotnicze, co zapoczątkowało rozwój ekonomiczno-przemysłowy Mielca. Granicę zachodnią omawianego obszaru tworzy zlewnia rzeki Wisłoki, która jest głównym źródłem wody dostarczanej mieszkańcom miasta Mielca i wsi Złotniki. Woda pobierana jest za pomocą ujęcia brzegowo-komorowego Wojsław,

\footnotetext{
${ }^{1}$ Klaudia Kujawska, Politechnika Rzeszowska

${ }^{2}$ Autor do korespondencji / corresponding author: Janusz Rak, Politechnika Rzeszowska, al. Powstańców Warszawy 6, 35-959 Rzeszów, tel. 17 8651449, e-mail: rakjan@prz.edu.pl
} 
którego wydajność planowana wynosi $26352 \mathrm{~m}^{3} / \mathrm{d}$. Dodatkowym źródłem zaopatrzenia w wodę jest ujęcie lewarowe o wydajności projektowanej $7200 \mathrm{~m}^{3} / \mathrm{d}$. Pobierana woda dostarczana jest do Stacji Uzdatniania Wody zlokalizowanej w Mielcu przy ul. Wolności 29, gdzie następuje szereg procesów mających na celu uzyskanie wody o odpowiedniej jakości [1-3].

Celem pracy jest przedstawienie analizy i ocena strat wody w wodociągu mieleckim w latach 2012-2014.

\section{Metody i dane wyjściowe}

Analizując zużycie wody przez odbiorów porównuje się kilka okresów rozliczeniowych, dzięki czemu istnieje możliwość wykrycia pewnych nieprawidłowości, które mogą świadczyć o przeprowadzeniu błędnych pomiarów, bądź o stratach wody [4]. Pomocne jest wówczas opracowanie wskaźników strat wody, do obliczenia których niezbędne są następujące wielkości [5-9]:

- woda wprowadzona do sieci $-\mathrm{V}_{\mathrm{wt}}$,

- zużycie na potrzeby własne $-\mathrm{V}_{\mathrm{w}}$,

- woda sprzedana $-\mathrm{V}_{\mathrm{sp}}$,

- woda sprzedana na potrzeby gospodarstw domowych $-\mathrm{V}_{\text {spgd, }}$,

- straty wody $-\mathrm{V}_{\text {str }}$,

- długości sieci: sieć magistralna - $M$, sieć rozdzielcza - R, całkowita długość $\mathrm{R}+\mathrm{M}$, podłączenia wodociągowe $-\mathrm{PW}$,

- liczba przyłączy wodociągowych - LPW.

Tabela 1 przedstawia bilans wykorzystania wody dysponowanej przez Miejskie Przedsiębiorstwo Gospodarki Komunalnej w Mielcu w latach 2012-2014.

W tabeli 2 zestawiono długości sieci wodociągu mieleckiego w latach 2012-2014.

Tabela 1. Bilans wykorzystania wody w latach 2012 - 2014, na podstawie [3]

Table 1. Balance water use in $2012-2014$, based on [3]

\begin{tabular}{|c|c|c|c|c|c|}
\hline \multirow{2}{*}{ Rok } & $\begin{array}{c}\text { Woda } \\
\text { wtłoczona } \\
\text { do sieci } \\
\mathbf{V}_{\text {wt }}\end{array}$ & $\begin{array}{c}\text { Woda sprze- } \\
\text { dana } \\
\mathbf{V}_{\text {sp }}\end{array}$ & $\begin{array}{c}\text { Woda zuży- } \\
\text { ta na cele } \\
\text { własne } \\
\mathbf{V}_{\text {wt }}\end{array}$ & $\begin{array}{c}\text { Straty } \\
\text { wody } \\
\mathbf{V}_{\text {str }}\end{array}$ & $\begin{array}{c}\text { Woda sprzedana } \\
\text { gospodarstwom } \\
\text { domowym } \\
\mathbf{V}_{\text {spgd }}\end{array}$ \\
\hline $\mathbf{2 0 1 2}$ & 3499800 & 2691800 & 505300 & 302700 & 2122100 \\
\hline $\mathbf{2 0 1 3}$ & 3574100 & 2651800 & 605600 & 316700 & 2093100 \\
\hline $\mathbf{2 0 1 4}$ & 3550400 & 2697700 & 629800 & 222900 & 2113800 \\
\hline
\end{tabular}


Tabela 2. Długości sieci wodociągu eksploatowanego przez MPGK w Mielcu w latach 2012-2014, na podstawie [3]

Table 2. Length of the water supply system operated by MPGK in Mielec in 2012-2014, based on [3]

\begin{tabular}{|l|c|c|c|c|c|c|}
\hline Rok & $\begin{array}{c}\text { Długość sieci } \\
\text { magistralnej } \\
\text { M [km] }\end{array}$ & $\begin{array}{c}\text { Długość sieci } \\
\text { rozdzielczej } \\
\text { R[km] }\end{array}$ & $\begin{array}{c}\text { Razem } \\
\text { M+R } \\
{[\mathbf{k m}]}\end{array}$ & $\begin{array}{c}\text { Długość podłą- } \\
\text { czeń wodocią- } \\
\text { gowych } \\
\text { PW [km] }\end{array}$ & $\begin{array}{c}\text { Razem } \\
\text { L [km] }\end{array}$ & $\begin{array}{c}\text { Liczba } \\
\text { podłączeń } \\
\text { LPW [szt.] }\end{array}$ \\
\hline $\mathbf{2 0 1 2}$ & 29,7 & 164,6 & 194,3 & 104,9 & 299,2 & 5381 \\
\hline $\mathbf{2 0 1 3}$ & 29,7 & 167,7 & 197,4 & 106,4 & 303,8 & 5457 \\
\hline $\mathbf{2 0 1 4}$ & 29,7 & 170,3 & 200 & 107,8 & 307,8 & 5527 \\
\hline
\end{tabular}

\section{Wskaźniki strat wody wg International Water Association}

Analiza strat wody została przeprowadzona z wykorzystaniem wskaźników zalecanych przez IWA. Należą do nich [5]: procentowy wskaźnik strat - WSW oraz wskaźniki określające straty $\mathrm{w}$ podsystemie dystrybucji: jednostkowy wskaźnik strat rzeczywistych - RLB, wskaźnik objętości wody niedochodowej NRWB, infrastrukturalny indeks wycieków - ILI oraz bilans strat nieuniknionych - UARL.

Procentowy wskaźnik strat

Jest to wskaźnik służący do określenia udziału strat wody w objętości wody wprowadzonej do sieci:

$$
\mathrm{WSW}=\frac{V_{s t r}}{V_{w t 1}} \cdot 100 \%
$$

Jednostkowy wskaźnik strat rzeczywistych

Wyznaczenie tego wskaźnika wymaga określenia dobowej wartości rzeczywistych strat $\mathrm{z}$ bilansem wodnym oraz liczby podłączeń wodociągowych [4,5]. Wyróżnione zostały następujące wersje wskaźnika RLB:

$$
\begin{aligned}
& \mathrm{RLB}_{1}=\frac{V_{\text {str }}}{(M+R) 365}\left[\mathrm{~m}^{3} / \mathrm{km} \cdot \mathrm{d}\right] \\
& \mathrm{RLB}_{2}=\frac{V_{\text {str }} \cdot 1000}{L P W}\left[\mathrm{dm}^{3} / \mathrm{d} \cdot \text { podłączenie wodociągowe }\right]
\end{aligned}
$$

Jeżeli liczba przyłączy przypadająca na kilometr sieci wynosi mniej niż 20, zaleca się stosowanie wskaźnika $\mathrm{RLB}_{1}$, natomiast, gdy wynosi ona minimum 20 stosuje się wskaźnik RLB 2 .

Wskaźnik objętości wody niedochodowej

$$
\mathrm{NRWB}=\frac{V_{w t \mathrm{t}}-V_{s p}}{V_{w t \mathrm{t}}} \cdot 100 \%
$$


Bilans strat nieuniknionych

Na roczną objętość wody, którą określa się jako straty nieuniknione składają się następujące składniki [4]:

- wycieki nieuniknione na przewodach sieci (nie uwzględniając przyłączy) $18 \mathrm{dm}^{3} / \mathrm{km} \cdot \mathrm{d} \cdot \mathrm{mH}_{2} \mathrm{O}$ ciśnienia,

- nieuniknione wycieki na podłączeniach (do granicy nieruchomości) $0,8 \mathrm{dm}^{3} /$ przyłącze $\cdot \mathrm{d} \cdot \mathrm{mH}_{2} \mathrm{O}$ ciśnienia,

- nieuniknione wycieki na podłączeniach (od granicy nieruchomości do głównego wodomierza) $-25 \mathrm{dm} / 3 \mathrm{~km} \cdot \mathrm{d} \cdot \mathrm{mH}_{2} \mathrm{O}$ ciśnienia.

$\mathrm{UARL}=[18 \cdot(\mathrm{M}+\mathrm{R})+25 \cdot \mathrm{PW}+0,8 \cdot \mathrm{LPW}] \cdot 0,365 \cdot \mathrm{p}\left[\mathrm{m}^{3} / \mathrm{rok}\right]$

gdzie: $\mathrm{p}$ - średnie ciśnienie w strefie pomiarowej $\left[\mathrm{mH}_{2} \mathrm{O}\right]$;

$\mathrm{p}=$ około $40 \mathrm{mH}_{2} \mathrm{O}$

0,365 - współczynnik przeliczeniowy na $\mathrm{m}^{3} \mathrm{i}$ na rok.

Infrastrukturalny indeks wycieków

Dzięki temu współczynnikowi możliwe jest przeprowadzenie porównania i oceny działań, jakie podejmuje się, aby obniżyć straty wody [4,5].

$$
\mathrm{ILI}=\frac{V_{\text {str }}}{U A R L}[-]
$$

W tabeli 3 przedstawiono kategorie i charakterystyczne wartości wskaźnika, umożliwiające przeprowadzenie prawidłowej oceny stanu technicznego wodociągu.

Tabela 3. Kategorie wartości wskaźnika według IWA, ILI, AWWA oraz WBI Banding System, na podstawie [10]

Table 3. Categories of IWA, IMI, AWWA and WBI Banding System, based on [10]

\begin{tabular}{|c|c|c|c|c|}
\hline \multirow{2}{*}{$\begin{array}{l}\text { Zakres i katego- } \\
\text { ria wg IWA }\end{array}$} & \multirow[b]{2}{*}{ Kategorie ILI } & \multicolumn{2}{|c|}{ Zakres wg WBI Banding System } & \multirow{2}{*}{$\begin{array}{l}\text { Zakres wg } \\
\text { AWWA }\end{array}$} \\
\hline & & $\begin{array}{l}\text { Kraje rozwija- } \\
\text { jaqce się }\end{array}$ & $\begin{array}{c}\text { Kraje rozwinię- } \\
\text { te }\end{array}$ & \\
\hline $\begin{array}{c}\text { ILI } \leq 1,5 \\
\text { stan bardzo dobry }\end{array}$ & \multirow{2}{*}{$\begin{array}{l}\text { stan bardzo } \\
\text { dobry }\end{array}$} & \multirow{2}{*}{$\mathrm{ILI} \leq 4,0$} & \multirow{2}{*}{$\mathrm{ILI} \leq 2,0$} & \multirow{2}{*}{$\mathrm{ILI} \leq 3,0$} \\
\hline $\begin{array}{c}1,5<\mathrm{ILI} \leq 2,0 \\
\text { stan dobry }\end{array}$ & & & & \\
\hline $\begin{array}{c}2,0<\mathrm{ILI} \leq 2,5 \\
\text { stan średni }\end{array}$ & stan dobry & $4,0<\mathrm{ILI} \leq 8,0$ & $2,0<\mathrm{ILI} \leq 4,0$ & $3,0<\mathrm{ILI} \leq 5,0$ \\
\hline $\begin{array}{c}2,5<\mathrm{ILI} \leq 3,0 \\
\text { stan słaby }\end{array}$ & \multirow{2}{*}{ stan słaby } & \multirow{2}{*}{$8,0<\mathrm{ILI} \leq 16,0$} & \multirow{2}{*}{$4,0<\mathrm{ILI} \leq 8,0$} & \multirow{2}{*}{$5,0<\mathrm{ILI} \leq 8,0$} \\
\hline $\begin{array}{c}3,0<\text { ILI } \leq 3,5 \\
\text { stan bardzo słaby }\end{array}$ & & & & \\
\hline $\begin{array}{c}\mathrm{ILI} \geq 3,0 \text { stan } \\
\text { niedopuszczalny }\end{array}$ & $\begin{array}{l}\text { stan niedopusz- } \\
\text { czalny }\end{array}$ & $\mathrm{ILI}>16,0$ & ILI > 8,0 & ILI > 8,0 \\
\hline
\end{tabular}




\section{Obliczenia wskaźników strat wody wg IWA - rok 2012}

Obliczenia wykonano na podstawie danych z tabeli 1 i tabeli 2.

- procentowy wskaźnik strat

$$
\mathrm{WSW}=\frac{302700}{3499800} \cdot 100=8,6 \%
$$

- jednostkowy wskaźnik strat rzeczywistych

$$
\begin{aligned}
& \mathrm{RLB}_{1}=\frac{302700}{194,3 \cdot 365}=4,3 \mathrm{~m}^{3} / \mathrm{km} \cdot \mathrm{d} \\
& \mathrm{RLB}_{2}=\left(\frac{302700 \cdot 1000}{5381}\right) / 365=154,1 \mathrm{dm} / \mathrm{d} \cdot \text { podłączenie wodociągowe }
\end{aligned}
$$

- wskaźnik objętości wody niedochodowej

$$
\mathrm{NRWB}=\frac{3499800-2691800}{3499800} \cdot 100=23,1 \%
$$

- bilans strat nieuniknionych

$$
\mathrm{UARL}=[18 \cdot 194,3+25 \cdot 104,9+0,8 \cdot 5381] \cdot 0,365 \cdot 40=152200,6 \mathrm{~m}^{3} / \mathrm{rok}
$$

- infrastrukturalny indeks wycieków

$$
\mathrm{ILI}=\frac{302700}{152200,6}=2
$$

Wskaźniki zalecane do porównania według IWA dla pozostałych lat wyznaczono analogicznie, a wyniki zamieszczono w tabeli 4.

Tabela 4. Wskaźniki strat wody dla wodociągu mieleckiego w latach 2012 - 2014, na podstawie $[2,3]$

Table 4. Water loss rates of water supply system in Mielec in 2012 - 2014, based on [2,3]

\begin{tabular}{|c|c|c|c|c|c|c|}
\hline Wskaźnik & $\begin{array}{c}\text { WSW } \\
{[\%]}\end{array}$ & $\begin{array}{c}\mathbf{R L B}_{\mathbf{1}} \\
{\left[\mathbf{m}^{\mathbf{3}} / \mathbf{k m} \cdot \mathbf{d}\right]}\end{array}$ & $\begin{array}{c}\mathbf{R L B}_{\mathbf{2}} \\
{\left[\mathbf{d m}^{\mathbf{3}} / \mathbf{d} \cdot \mathbf{P W}\right]}\end{array}$ & $\begin{array}{c}\text { NRWB } \\
{[\%]}\end{array}$ & $\begin{array}{c}\text { UARL } \\
{\left[\mathbf{m}^{3} / \mathbf{r o k}\right]}\end{array}$ & $\begin{array}{c}\text { ILI } \\
{[-]}\end{array}$ \\
\hline $\mathbf{2 0 1 2}$ & 8,6 & 4,3 & 154,1 & 23,1 & 152200,6 & 2 \\
\hline $\mathbf{2 0 1 3}$ & 8,9 & 4,4 & 159 & 25,8 & 154450,5 & 2,1 \\
\hline $\mathbf{2 0 1 4}$ & 6,3 & 3,1 & 110,5 & 24 & 156462,4 & 1,4 \\
\hline
\end{tabular}

\section{Jednostkowe wskaźniki strat wody}

W celu dokładnego przedstawienia funkcjonowania systemu zaopatrzenia w wodę wyznacza się jednostkowe wskaźniki strat wody, do których należą [26]:

Ilość wody wprowadzanej do sieci

$$
\mathrm{q}_{\mathrm{wtt}}=\frac{\mathrm{V}_{\mathrm{wtt}} \cdot 1000}{\mathrm{LM} \cdot 365}\left[\mathrm{dm}^{3} / \mathrm{mk} \cdot \mathrm{d}\right]
$$

Ogólna ilość sprzedanej wody

$$
\mathrm{q}_{\mathrm{sp}}=\frac{\mathrm{V}_{\mathrm{sp}} \cdot 1000}{\mathrm{LM} \cdot 365}\left[\mathrm{dm}^{3} / \mathrm{mk} \cdot \mathrm{d}\right]
$$


Ilość wody sprzedanej na potrzeby gospodarstw domowych

$$
\mathrm{q}_{\mathrm{spgd}}=\frac{\mathrm{v}_{\text {spgd }} \cdot 1000}{\mathrm{LM} \cdot 365}\left[\mathrm{dm}^{3} / \mathrm{mk} \cdot \mathrm{d}\right]
$$

Ilość strat wody

$$
\mathrm{q}_{\mathrm{str}}=\frac{\mathrm{v}_{\mathrm{str}} \cdot 1000}{\mathrm{LM} \cdot 365}\left[\mathrm{dm}^{3} / \mathrm{mk} \cdot \cdot \mathrm{d}\right]
$$

Ilość wody wykorzystywanej na cele własne wodociągu

$$
\mathrm{q}_{\mathrm{wt}}=\frac{\mathrm{V}_{\mathrm{wt}} \cdot 1000}{\mathrm{LM} \cdot 365}\left[\mathrm{dm}^{3} / \mathrm{mk} \cdot \mathrm{d}\right]
$$

Ilość wody niedochodowej

$$
\mathrm{q}_{\mathrm{nd}}=\frac{\left(\mathrm{V}_{\mathrm{wtt}}-V_{s p}\right) \cdot 1000}{\mathrm{LM} \cdot 365}\left[\mathrm{dm}^{3} / \mathrm{mk} \cdot \cdot \mathrm{d}\right]
$$

\section{Obliczenia jednostkowych ilości wody - rok 2012}

Liczba mieszkańców korzystających z sieci wodociągowej w 2012 wynosiła 60967. Do wykonania obliczeń wykorzystano dane zawarte w tabeli 1.

- ilość wody wprowadzanej do sieci

$$
\mathrm{q}_{\mathrm{wtt}}=\frac{3499800 \cdot 1000}{60967 \cdot 365}=157,3 \mathrm{dm}^{3} / \mathrm{mk} \cdot \mathrm{d}
$$

- ogólna ilość sprzedanej wody

$$
\mathrm{q}_{\mathrm{sp}}=\frac{2691800 \cdot 1000}{60967 \cdot 365}=121,0 \mathrm{dm}^{3} / \mathrm{mk} \cdot \mathrm{d}
$$

- ilość wody sprzedanej na potrzeby gospodarstw domowych

$$
\mathrm{q}_{\mathrm{spgd}}=\frac{2122100 \cdot 1000}{60967 \cdot 365}=95,4 \mathrm{dm}^{3} / \mathrm{mk} \cdot \mathrm{d}
$$

- straty wody

$$
\mathrm{q}_{\mathrm{str}}=\frac{302700 \cdot 1000}{60967 \cdot 365}=13,6 \mathrm{dm}^{3} / \mathrm{mk} \cdot \mathrm{d}
$$

- ilość wody wykorzystywanej na cele własne wodociągu

$$
\mathrm{q}_{\mathrm{wt}}=\frac{505300 \cdot 1000}{60967 \cdot 365}=22,7 \mathrm{dm}^{3} / \mathrm{mk} \cdot \mathrm{d}
$$

- ilość wody niedochodowej

$$
\mathrm{q}_{\mathrm{nd}}=\frac{(3499800-2691800) \cdot 1000}{60967 \cdot 365}=36,3 \mathrm{dm}^{3} / \mathrm{mk} \cdot \mathrm{d}
$$

Obliczone dotyczące jednostkowych ilości wody dla pozostałych lat wykonano analogicznie, a wyniki umieszczono w tabeli 5.

Tabela 6 zawiera natomiast zestawienie wartości jednostkowego wskaźnika obciążeń hydraulicznych sieci, wskaźnika strat odnoszący się do całkowitej długości sieci oraz rzeczywistych strat wody w latach 2012 - 2014. Do obliczeń wykorzystano następujące wzory: 
Tabela 5. Zestawienie jednostkowych wskaźników ilości wody w latach 2012 - 2014

Table 5. Summary of unit indicators of the amount of water in 2012 -2014

\begin{tabular}{|c|c|c|c|c|}
\hline & & \multicolumn{3}{|c|}{ Rok } \\
\hline & & 2012 & 2013 & 2014 \\
\hline \multicolumn{2}{|c|}{ Liczba mieszkańców korzystających z wodociągu LM } & 60967 & 60828 & 60564 \\
\hline \multirow{6}{*}{ 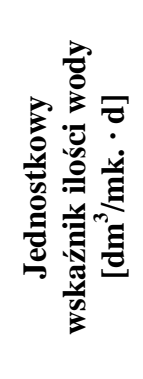 } & $\boldsymbol{q}_{w t t}$ & 157,3 & 161,0 & 160,6 \\
\hline & $\boldsymbol{q}_{s p}$ & 121,0 & 119,4 & 122,0 \\
\hline & $q_{\text {spgd }}$ & 95,4 & 94,3 & 95,6 \\
\hline & $\boldsymbol{q}_{s t r}$ & 13,6 & 14,3 & 10,1 \\
\hline & $q_{w l}$ & 22,7 & 27,3 & 28,5 \\
\hline & $q_{n d}$ & 36,3 & 41,5 & 38,6 \\
\hline
\end{tabular}

Tabela 6. Jednostkowe wskaźniki hydraulicznych obciążeń oraz rzeczywiste straty wody w latach 2012 - 2014, na podstawie [2,3]

Table 6. Indicators of individual hydraulic loads and real water losses in $2012-2014$, based on $[2,3]$

\begin{tabular}{|c|c|c|c|c|}
\hline Rok & $\begin{array}{c}\mathbf{q}_{\text {o }} \\
{\left[\mathbf{m}^{\mathbf{3}} / \mathbf{k m} \cdot \mathbf{d}\right]}\end{array}$ & $\begin{array}{c}\mathbf{q}_{\text {strL }} \\
{\left[\mathbf{m}^{\mathbf{3}} / \mathbf{k m} \cdot \mathbf{d}\right]}\end{array}$ & $\begin{array}{c}\mathbf{V}^{\prime}{ }_{\text {str }} \\
{\left[\mathbf{m}^{3} / \mathbf{r o k}\right]}\end{array}$ & $\begin{array}{c}\mathbf{q}^{\prime}{ }_{\text {strL }} \\
{\left[\mathbf{m}^{3} / \mathbf{k m} \cdot \mathbf{d}\right]}\end{array}$ \\
\hline $\mathbf{2 0 1 2}$ & 49,3 & 2,8 & 150499,4 & 1,4 \\
\hline $\mathbf{2 0 1 3}$ & 49,6 & 2,9 & 162249,5 & 1,5 \\
\hline $\mathbf{2 0 1 4}$ & 48,6 & 2 & 66437,6 & 0,6 \\
\hline
\end{tabular}

Wskaźnik obciążenia hydraulicznego

$$
\mathrm{q}_{\mathrm{o}}=\frac{V_{w t \mathrm{t}}}{L_{M+R} \cdot 365}\left[\mathrm{~m}^{3} / \mathrm{km} \cdot \mathrm{d}\right]
$$

Wskaźnik strat wody dla całkowitej długości sieci

$$
\mathrm{q}_{\mathrm{strL}}=\frac{V_{s t r}}{L \cdot 365}\left[\mathrm{~m}^{3} / \mathrm{km} \cdot \mathrm{d}\right]
$$

Rzeczywiste straty wody

$$
\mathrm{V}^{\prime}{ }_{\mathrm{str}}=\mathrm{V}_{\mathrm{str}}-\mathrm{UARL}\left[\mathrm{m}^{3} / \mathrm{rok}\right]
$$

Ponadto w tabeli zamieszczono również wskaźnik jednostkowy strat wody dla całkowitej długości sieci z uwzględnieniem start rzeczywistych, obliczony według zależności (16). 


$$
\mathrm{q}^{\prime}{ }_{\mathrm{strL}}=\frac{V \prime_{\text {str }}}{L \cdot 365}\left[\mathrm{~m}^{3} / \mathrm{km} \cdot \mathrm{d}\right]
$$

Do wyznaczenia wskaźników na podstawie wzorów (13), (14), (15), (16) wykorzystano dane zawarte w tabelach 1, 2 oraz 4. Obliczenia dla roku 2012 przedstawiają się następująco:

- wskaźnik obciążenia hydraulicznego

$$
\mathrm{q}_{\mathrm{o}}=\frac{3499800}{194,3 \cdot 365}=49,3 \mathrm{~m}^{3} / \mathrm{km} \cdot \mathrm{d}
$$

- wskaźnik strat wody dla całkowitej długości sieci

$$
\mathrm{q}_{\mathrm{strL}}=\frac{302700}{299,2 \cdot 365}=2,8 \mathrm{~m}^{3} / \mathrm{km} \cdot \mathrm{d}
$$

- rzeczywiste straty wody

$$
\begin{aligned}
& \mathrm{V}_{\text {str }}^{\prime}=302700-152200,6=150499,4 \mathrm{~m}^{3} / \mathrm{rok} \\
& \mathrm{q}_{\text {strL }}^{\prime}=\frac{150499,4}{299,2 \cdot 365}=1,4 \mathrm{~m}^{3} / \mathrm{km} \cdot \mathrm{d}
\end{aligned}
$$

Obliczenia dla lat 2013 i 2014 wykonano analogicznie, a wyniki zostały umieszczone w tabeli 6 .

\section{Podsumowanie}

- Procentowy udział strat wody w ilości wody wprowadzonej do mieleckiego wodociągu w latach 2012 - 2014 mieścił się w zakresie 6,3\% $\div 8,9 \%$.

-W odniesieniu do długości sieci wartość jednostkowego wskaźnika strat rzeczywistych zawierał się w przedziale $3,1 \div 4,4 \mathrm{~m}^{3} / \mathrm{km} \cdot \mathrm{d}$. Biorąc pod uwagę liczbę przyłączy wodociągowych wskaźnik ten osiągał wartości z zakresu $110,5 \div 159 \mathrm{dm}^{3} / \mathrm{d} \cdot \mathrm{PW}$. W obu przypadkach widoczny jest początkowy niewielki wzrost wartości obliczeniowej, po czym z roku 2013 na 2014 następuje zmniejszenie wskaźnika.

-W latach 2012 - 2014 procentowy udział objętości wody nie przynoszącej dochodów utrzymywał się na w miarę stałym poziomie w granicy $23,1 \div 25,8 \%$.

-W latach 2012 - 2014 wartości wskaźnika ILI mieściły się w zakresie $2,1 \div 1,4 \%$. Na podstawie kategorii podanych prze IWA, możemy zauważyć, że w roku 2014 mielecka sieć wodociągowa zaliczała się do sieci o bardzo dobrym stanie technicznym, natomiast $\mathrm{w}$ latach wcześniejszych był średni (2013 r.) i dobry (2012 r.). Biorąc pod uwagę zakresy ustanowione przez WBI dla rozwijających się krajów oraz AWWA stan wodociągu w podanym okresie czasu był bardzo dobry. Natomiast w przypadku krajów rozwiniętych w roku 2012 i 2014 sieć posiadała bardzo dobry stan, a w 2013 r. był on dobry.

- Objętości wody zużywanej na poszczególne cele w przeliczeniu na jednego konsumenta przedstawiają szczegółową sytuację eksploatacyjną sieci wodociągowej eksploatowanej przez MPGK w Mielcu. Najmniejsze wartości odnotowano w przypadku jednostkowych ilości strat. Mieściły się one w zakresie $10,1 \div 14,3 \mathrm{dm}^{3} / \mathrm{mk}$. d d. Biorąc pod uwagę objętości wody wykorzystywanej 
przez jednego mieszkańca $\mathrm{w}$ gospodarstwie domowym były one około 7,5-krotnie większe i zawierały się w przedziale $94,3 \div 95,6 \mathrm{dm}^{3} / \mathrm{mk} \cdot \cdot \mathrm{d}$.

-W latach 2012 - 2013 wartości jednostkowego wskaźnika obciążeń hydraulicznych utrzymywały się na stałym poziomie. Natomiast wskaźnik strat wody odnoszący się do całkowitej długości sieci wahał się w granicy $2 \div 2,8 \mathrm{~m}^{3} / \mathrm{km} \cdot \mathrm{d}$.

-W analizowanym okresie czasu można zaobserwować początkowy niewielki wzrost strat rzeczywistych, a następnie dwukrotny spadek do wartości $66437,6 \mathrm{~m}^{3} /$ rok. Przyczyną tak dużej różnicy może być poprawa stanu technicznego rurociągów, a co za tym idzie zmniejszenie ubytku wody w wyniku przecieków.

\section{Literatura}

[1] Kowalczyk A., Mielec, w: Nowicki Z. (red.), Informator Państwowej Służby Hydrogeologicznej. Wody podziemne miast Polski. Miasta powyżej 50000 mieszkańców. Państwowy Instytut Geologiczny, Warszawa 2009, s. 219-235.

[2] Kujawska K., Praca magisterska: Analiza i ocena zaopatrzenia w wodę miasta Mielca. Rzeszów 2016.

[3] Materiały udostępnione przez Zakład Wodociągów i Kanalizacji w Mielcu.

[4]Piechurski F., Sposoby zmniejszania strat wody. Rynek Instalacyjny, nr 11 i 12, 2011, s. 74-76, 72-75.

[5]Rak J., Problematyka ryzyka w wodociągach. Oficyna Wydawnicza Politechniki Rzeszowskiej, Rzeszów 2014.

[6]Rak J. Metoda planowania remontów sieci wodociągowej na przykładzie miasta krosna, Czasopismo Inżynierii Lądowej, Środowiska i Architektury - Journal of Civil Engineering, Environment And Architecture. JCEEA, z. 61 (1/2015), s. 225-232 DOI: $10.7862 / \mathrm{rb} .2014 .15$.

[7]Rak, J., Pietrucha-Urbanik, K. New directions for the protection and evolution of water supply systems - smart water supply. Czasopismo Inżynierii Lądowej, Środowiska i Architektury - Journal of Civil Engineering, Environment And Architecture. JCEEA, z. 62 (3/I/2015), pp. 365-373. DOI: 10.7862/rb.2015.121.

[8]Rak J., Tunia A., Analiza i ocena strat wody w wodociągu Rzeszowa. Instal 2012, 5, s. $42-45$.

[9] Studziński A., Pietrucha-Urbanik K. Preventive maintenance and reliability of water supply system elements. Czasopismo Inżynierii Lądowej, Środowiska i Architektury - Journal of Civil Engineering, Environment And Architecture. JCEEA, z. 62 (3/I/2015), pp. 429-436. DOI: 10.7862/rb.2015.126.

[10] Pietrucha-Urbanik K., Studziński A.: Analiza strat wody wodociągu krośnieńskiego. Gaz, Woda i Technika Sanitarna, 10/2012, s. 452-454. 


\section{ANALYSIS AND ASSESSMENT OF WATER LOOSES IN WATER SUPPLY SYSTEM IN MIELEC}

\section{S u m m a r y}

In order to reduce the costs associated with water treatment and supply, modernization should be performed on the basis of water losses analysis. In the paper analysis and assessment of water losses, performed on the basis of data provided by the Department of Water and Sewer in Mielec was presented. The obtained data relate to the structure of the water supply system of the Mielec city and the quantitative water balance in the years 2012-2014. According to provided data, the water losses indicators were appointed according to International Water Association. The basic indicators of water loss were established and referenced to the proposed indicators by the International Water Association. (IWA), as: percentage (WS), Infrastructure Leakage Index(RLB), the water volume-profit (MRWB), Unavoidable Annual Real Losses (UARL), infrastructure leakage index (ILI). On the basis of the categories specified for IWA, it can be noted that in 2014 water supply network in Mielec was the networks with very good technical condition. Received values of water losses in Mielec water supply system are comparable to the values of indicators obtained in other systems of collective water supply in Poland.

Keywords: water losses, water losses indicators, water consumption, water supply system

Przestano do redakcji: $10.03 .2016 \mathrm{r}$.

Przyjęto do druku: 15.09.2016 r.

DOI: $10.7862 / \mathrm{rb} .2016 .143$ 